\title{
THE IMPACT OF CLASSROOM ACTIVITIES ON THE IMPROVEMENT OF READING SKILLS IN STUDENTS WITH ATTENTION HYPERACTIVITY DISORDER (ADHD)
}

\author{
Doğuş Aydın*
}

\begin{abstract}
ADHD is a disorder diagnosed in $21^{\text {st }}$ century students in a notable manner. This increase in diagnosis has recently led the scholars to study these kinds of students' learning skills extensively. Reading as a skill is highly problematic for such students. Thus, this research is discussing the classroom reading strategies that must be adopted for the students who have this disability. Three students volunteered to participate in the research. These students were all diagnosed with the disorder by a psychologist. As a result of the research conducted, the students learned how to read strategically. The strategies implemented are metacognitive, cognitive and social-affective. Due to their application, such students can achieve higher success in reading comprehension questions.
\end{abstract}

Key words: attention deficit hyperactivity disorder reading skills, reading comprehension strategies, ADHD learning skills, reading comprehension

\section{Literature Review}

ADHD is a developmental disorder characterized by difficulties with inattention, impulsivity, and hyperactivity. (Barkley, 1997; DSM-IV-TR, APA, 2000) Individuals with ADHD exhibit combinations of the following behaviors:

- Fidgeting with hands or feet or squirming in their seat (adolescents with ADHD may appear restless);

- Difficulty remaining seated when required to do so;

- Difficulty sustaining attention and waiting for a turn in tasks, games, or group situations;

- Blurting out answers to questions before the questions have been completed;

- Difficulty following through on instructions and in organizing tasks;

- Shifting from one unfinished activity to another;

- Failing to give close attention to details and avoiding careless mistakes;

\footnotetext{
* PhD Candidate at Istanbul Aydin University, English Teacher \& Language Advisor, Istanbul, Turkey, e-mail:dogus@dogusaydin.com.
} 
- Losing things necessary for tasks or activities;

- Difficulty in listening to others without being distracted or interrupting;

- Wide ranges in mood swings;

- Great difficulty in delaying gratification. (US Department of Education, 2004/2005/2006/2008)

As a result of these behavioral problems, students cannot acquire academic skills easily and well in classrooms. This lack of acquiring academic skills can be seen with reading comprehension skills extensively. Students cannot possibly comprehend the text while reading it. For Bremer and Stern (1976) studies have shown that children with ADHD often omit words or phrases, as well as skip lines during the reading of a passage. When compared with other childhood psychiatric problems, including depression, anxiety and disruptive behavior disorders, researchers (Barkley, 2006; Breslau et al., 2009) found that attention problems had the strongest impact on a child's future academic success. (Burns, 2010) Even after the mechanics of reading have been mastered, many children with ADHD have trouble understanding the text, making connections within the story, and relating what they are reading to what they already know (http:// www.additudemag.com/adhd/983.html). There could be many causes leading to the inability to understand or remember what the students having this problem read. Some of them can be categorized as adolescents with ADHD who can only comprehend isolated words. Subtle difficulties were observed, however, on measures of text reading rate and accuracy as well as on silent reading comprehension, but scores remained in the average range. (Ghelani, Sidhu, Jain and Tannock, 2004) Children with ADHD often have difficulty sustaining attention, blocking out distractions of both an internal and external nature, understanding and organizing thought patterns, and recalling information while reading text (Zentall, 1993). As a result, children with ADHD often have difficulties with remembering what they read. This weakness in comprehension is further compounded by poor strategy use (Levine, 2002). The performance of children with ADHD, without comorbid language impairments, declined as the length of the passage increased (Cherkes-Julkowski et al., 1995). US Department of Education suggests (2008) to break down assignments into smaller, less complex tasks. For example, allow students to complete five math problems before presenting them with the remaining five problems. The ADHD group had lower scores on silent reading comprehension relative to the normal controls, but their scores were also within the average range. Our findings for the ADHD group are similar to those of a recent study (e.g. Willcutt et al., in press) that reports lower scores for the ADHD group (albeit still within the average range) than for a normal control group on silent reading comprehension. Subtle difficulties were evident for adolescents with ADHD on measures of text reading accuracy and reading rate for words and text. In Ghelani et 
al. (2004) research, ADHD students did not show any problem with reading comprehension. However, there were problems with accuracy and fluency. That is, their scores on these measures were within the average range although lower than those of the normal controls and, in some cases, lower than the normative sample mean (i.e. Mean $1 / 4100$, SD 1/4 15). (Ghelani et al. 2004)

\section{Methodology}

Three subjects were selected to participate in the research to come up with good results. The initial cause of this was to gain a better insight into the effect of learning strategies on the subjects who have been chosen. Their ages ranged from nine, ten and eleven respectively and two of them were girls. Another factor that might have affected the research was the fact that one of three was educated in a private school; whereas, the rest of the students were studying in public schools. The reason why this was considered significant was the approach of the teachers who may have had a better impact on ADHD children. Silent reading was applied during the research. As the first step of the research, all these students were given a text suitable for their level of English. All possible classroom distractors in the classroom environment were removed to prevent the students from being distracted and losing concentration on the text. The second step of the experiment was to ask them to read the text silently and as the following they were asked to answer five comprehension questions about the text. They were not allowed to reread after or before the comprehension questions. After reading the text, they were interviewed to understand how they had read.

At the beginning, the students were warned that they would be asked comprehension questions related to the text. The accuracy rate evaluated in the answers of all the three students were surprisingly similar. One of the questions was correct and four incorrect.

After clarifying the students' deficiency in reading comprehension, the following step was to conduct an interview with each student by asking several questions. At the beginning of the interview, the aim of it was told to the students with a simple language as in the following way 'This would help you in your reading activities that you have lack of.' After making the students aware of the fact that they needed help, the interview questions were more effective as the questions of the interview below were selected with the aim of leading the students to be aware of how they can be better at reading comprehension.

\section{Interview Questions}

1.How do you read texts and books?

2.How long can you read a book without stopping? 
3.What do you do if you don't know the meanings of the words in a text?

4.Where do you read at home?

5.How fast can you read?

6.What do you do to understand the book if you don't like it?

7.What do you try to learn about the book before you start reading?

Students' answers gave us new ideas about improving their reading skills which was to teach them reading strategies.

\section{Result and Discussion}

Before the experiment all objects which could potentially distract students from doing the tasks were removed from the classroom. Students' behavior while reading was observed with the aim of detecting and describing their specific reactions. First, their eye movement was not focusing on what they were reading. It was realized that they were not sometimes looking at the text. One of the students was even drawing something on the paper while reading by putting the text aside. Therefore, observing the students closely and trying to make eye contact with them during the class can be the roles that a teacher should play to improve their concentration on the task that they are performing.

The observations continued by noticing that the students were disturbed if there was a noise. Moreover, they were asking the teacher unrelated questions while they were reading by giving themselves a short break. It was noticed that they were not thinking of what they were reading if the text was not motivating at all. That is why, motivation was one of the most essential point of a reading text otherwise they could be easily distracted. As a conclusion of these observations, having eye contact with them during the class, giving them motivating text or letting them free to choose the text that they want to read would be the roles of the teacher to conduct an efficient class in the classroom to improve such students' reading comprehension skills.

The interview revealed significant findings as well. When the first question was asked with the aim of understanding what students thought, the first student commented on the question by saying that she looked at the pictures and underlined the words and did not attempt to translate. The second student who was aged 10 made a similar statement as the first by saying that her attention was distracted by the pictures. Furthermore, she said that she could understand better if she read aloud. The third also remarked that he did not focus on the words too much. He rather focused on the pictures and read fast. A note worth mentioning was that while the interview questions were asked, the researcher was trying to relieve the students and lead them to give the most accurate 
answers. Otherwise, it could be probable that they would answer the questions in terms of teachers' expectations or social norms.

The second question was easy to be misinterpreted by the children and they replied with the words that a teacher would like to hear. However, when they were warned that they should give the true answer, they started commenting. The first student commented that she could not read for more than 15 minutes. If she did, she would be bored so she would not understand well. The second student said that she could read for 30 minutes without stopping. The reason why she could read longer was her positive attitude towards reading that had been observed by the researcher for 2 years while they were studying together. The third had the chance to read more as he had learned to read with the help of his mother at an early age. Therefore, his answer was quite different from those of the others. He told that he could read till the end of the text or book if it were attractive. These findings indicated that the students paid attention to something that was more interesting. As a response to the answers of the students for this question, a strategy was taught to them namely making them read chapter by chapter and summarize what they learned. A cognitive skill to summarize is an essential step for ADHD students to acquire. As one subject asserted, she understood better when she read by separating the text into smaller parts. Therefore, it was significant to split the text into smaller parts.

The following question displayed another factor that children with ADHD are affected by. The first student responded to the third question that she pretended as if she underlined the words in her mind. This meant that she was skimming through her mind if the words had more importance in the context. She could guess the meaning of the whole well enough by understanding the separate words. The second and third students also did the same. They all indicated that they obtained the meaning from the context clearly as they paid attention to more important words. However, they did not pay attention to details while processing the information. This led them not to get the main gist of the text or understand the detailed meanings. As a solution to this problem, the students should be encouraged to use social-affective strategies which are self-talk or collaboration. While talking to themselves or with others in the classrooms, they could be confirming or noticing the minor details or main gist of the text.

Another question showed that they all could not read at a place where everything was put in an order such as a desk on which all the notebooks, pencils or books were placed in an order. On the contrary, they were looking for a place where they could do two things simultaneously for instance a sofa where they could read and watch TV at the same time. The first student told that she tried to read at the table due to the fact that she was asked by her parents. However, she would like to read on the sofa. The second student generally preferred reading in her room. The third read in bed where he could take a nap while reading. However, 
all these ways of reading could not prove to be useful. For a better result, the students' parents can be asked by teachers to encourage their children to read at the table in their room on which no distractors can be found like phone, computer, unrelated books or such things. This can make them concentrate on reading. As motivation is significant and independent learning environment can be aimed to be created, extensive reading activities should be encouraged by teachers and parents for the students with ADHD.

The first student answered the fifth question by explicitly emphasizing that she did not find many things worth reading. Thus, she did not feel encouraged to read and she preferred looking at the pictures rather than reading. The second subject said that she did not read so fast. Instead she struggled to understand better. The third had a similar answer. However, he also read fast if the topic were not motivating. The children with ADHD tend to read faster if the texts or books are not attractive enough. Thus, it is more important to let them read a more enjoyable one. The sixth question was related to the fifth one. All students gave similar answer which supported the idea that the text should be motivating to make them scan and read intensively.

The seventh question was anticipated beforehand and they all gave similar answer indicating that they did not make any effort related to the pre-reading activities such as checking the topic and the author. Hence, the strategy that was used was to make them read about the topic on the internet and enable them to activate their schemata. This schemata activation strategy could help them be better at reading comprehension skills.

To sum up, it was understood in this experiment that these kinds of students read poorly, and the reading strategies can make them acquire better reading comprehension skills. Teaching reading strategies would help them in their reading skills. As Ghelani et al. (2004) have suggested, reading comprehension difficulties have been identified in two common and frequently overlapping childhood disorders: reading disability (RD) and attention-deficit/hyperactivity disorder (ADHD). The essential problems that arise while ADHD students try to read is that they cannot scan, skim through properly, understand the main gist of the text, do intensive reading, concentrate well. The facts that underlie these inabilities are the ADHD students' reflexes.

To list what should be done in the classrooms, it can be worth saying that diagnosing child with ADHD among others in the classroom is the first thing that a teacher should do before building up the strategies. As the students with this disorder can show certain behaviors like fidgeting with pen, holding something in their mouth, not having eye contact easily, thinking of something else, not being active listener despite watching you, being interested in something else while performing a classroom task and being distracted easily, they can be easy to be diagnosed. After the diagnosis, an individualized program should be made 
for such students. The classroom materials can be based on what they like, and they can be free to choose the text they like accordingly. For instance, Extensive reading activities can be encouraged for developing students' reading skills. Third, teacher should contact the students' parents and teacher and parents can work together. Places which are quiet and free of distraction should be provided with the help of the parents. On condition that these students are better independent learners, this process can be more influential as they can work individually without the distraction of others. However, it should not be understood wrong because the social-affective strategies and interdependency between student and teacher should not be underestimated. For instance, these students should be encouraged to summarize what they have understood and tell their parents or teachers at regular intervals while or after reading. This can be a good example of collaboration for them. It can also make them sustain their attention. Furthermore, self-talk can be encouraged, as well in order to confirm whether they have understood the part they have read or not. Finally, reading strategies which are cognitive, metacognitive and social-affective should be taught them by the teacher in the classroom to get more positive results on reading comprehension skills.

\section{Further Suggestions}

The students with ADHD can gain some positive results in reading that is crucial for them to understand new knowledge. Hence, the strategies have to be implemented by the teachers and parents. They should learn how to read properly. Separating the texts into smaller units, excluding the student from the surrounding in the place where he/she is reading, and summarizing are key points that can be achieved with better scanning and intensive reading. Furthermore, another role of teachers and parents is to provide with the students more motivating texts and books. For the classroom teaching, individual Education System (IES) is another step that has to be maintained. The children must be individualized within the group. Another point which can be taken into consideration is that the children should be encouraged to read aloud rather than silently as it is inferred from their comments during the interview.

\section{References}

Barkley, R. A. (1997). ADHD and the nature of self-control. New York: Guilford Press.

Bremer, D. A., Stern, J. A. (1976). Attention and distractibility during reading in hyperactive boys. Journal of Abnormal Child Psychology, 381-387.

Buchoff, R. (1990). Attention deficit disorder: Help for the classroom teacher. Childhood Education, 67, 86-90. 
Burns, M. B. (2010). Reading difficulties in children with ADHD. 55th Annual IRA Conference. Chicago,Illinois.

Cherkes-Julkowski, M., Stolzenberg, J., Hatzes, N., \& Madaus, J. (1995). Methodological issues in assessing the relationship among ADD, medication effects and reading performance. Learning Disabilities: A Multidisciplinary Journal, 6,21-30.

Cruger, M. (n.d.). Reading,Writing,Math: How to improve reading skills in children with ADHD or Larning Disabilities. Retrieved Ocak 1, 2016, from Addidute: http:// www.additudemag.com/adhd/article/983.html

Ghelani, K., Sidhu, R., Jain, U., \& Tannock, R. (2004). Reading comprehension and reading related abilities in adolescents with reading disabilities and AttentionDeficit/Hyperactivity Disorder. Dyslexia, 364-384.

Levine, M. D. (2002). Educational care: A system for understanding and helping children with learning problems at home and in school. Cambridge: Cambridge,MA: Educators Publishing Service Inc.

US Department of Education (2008). Teaching children with Attention Deficit Hyperactivity Disorder: Instructional strategies and practices. Washington D.C.: U.S. Department of Education:Office of Special Education and Rehabilitative Services, Office of Special Education Programs. Available at: https://www2.ed.gov/ rschstat/research/pubs/adhd/adhd-teaching.htm

Willcutt, E., Pennington, B., Boada, R., Ogline, J., Tunick, R., Chhabildas, N., \& Olson, R. (2001). A comparison of the cognitive deficits in reading disability and attention deficit/hyperactivity disorder. Journal of Abnormal Psychology, 110, 157-172.

Zentall, S. (1993). Research on the educational implications of attention deficit hyperactivity. Exceptional Children, 143-153. 